\title{
Yardstick Competition, Corruption, and Electoral Incentives
}

\author{
NGO VAN LONG \\ BODHISATTVA SENGUPTA
}

CESIFO WORKING PAPER NO. 2345

CATEgory 2: PuBlic CHOICE

JULY 2008
An electronic version of the paper may be downloaded
- from the SSRN website:
- from the RePEc website:
- from the CESifo website:
www.SSRN.com
www.RePEc.org
www.CESifo-group.org/wp




\title{
Yardstick Competition, Corruption, and Electoral Incentives
}

\begin{abstract}
This paper investigates the relationship between electoral incentives, institutions and corruption. We assume that voters use a yardstick criterion. The incumbent provides a public good and extracts rent, which are financed by imposing a distortionary tax. We demonstrate the possibility that yardstick competition itself fails to restrict rent seeking. We complement the static setting with a dynamic scenario where each incumbent politician faces an election after a finite, fixed term. Under relative performance evaluation, dynamic incentives impose more restriction on rent appropriation in comparison to the static case.
\end{abstract}

JEL Code: H11, H73, H77.

Keywords: yardstick competition, rent-seeking, public good, electoral incentives.

Ngo Van Long

Department of Economics

McGill University

855 Sherbrooke Street West

Montreal, Quebec H3A 2T7

Canada

ngo.long@mcgill.ca
Bodhisattva Sengupta

Kemmy Business School

University of Limerick

Limerick

Ireland

bodhisattva.sengupta@mail.mcgill.ca 


\section{Introduction}

The present work investigates the relationship between electoral incentives, political institutions and political corruption. While the traditional textbook view of the politician as a benevolent maximizer of social welfare is passé, there is no consensus about the alternative behaviour. At one extreme, one encounters the Virginia School's view of the politician as a Leviathan, maximizing the government size with a high degree of corruption. At the other extreme, there is the Chicago School's view that politicians' behaviour is shaped by electoral incentives and party politics. If politicians are indeed rational, then political competition must align their interest with that of the majority of voters (otherwise they forfeit elections). In other words, elections serve as disciplinary stick.

The above conclusion can be used to prescribe welfare maximizing political institutions. High degrees of economic decentralization accompanied by the creation of multiple political jurisdictions ("deepening of democracy", to borrow a phrase from the United Nations Human Development Report (2002) make local politicians more accountable to their lower level constituencies. As a result, the degree of political competition increases, yielding a higher welfare for the population and reducing corruption.

A growing literature, known as the political agency literature, investigates how elections may serve as an appropriate stick. The idea is to treat the voters as principals and the politicians as agents. According to this point of view, rent appropriation by politicians occurs only if there exists imperfect information. Barro (1973) and Ferejohn (1986) developed models of moral hazard where the politicians' effort levels are not observable by voters, and that allow the politicians to capture some rent. Here, the politicians care only for rent and nothing else. In a dynamic sense, it is optimal for the voters to offer a positive rent to the election-seeking politicians in order to avoid higher rent extraction in the current period.

On the other hand, the informational asymmetry may take the form of pure adverse selection and an associated signalling game. Such asymmetries are exploited in the electoral cycle model of Rogoff (1990) and Rogoff and Sibert (1988). Before the elections, the politicians try to signal their competence, and engage in lower rent extraction than post election time period. The role of elections, in such models, is to choose the right type of politicians.

A related strand of literature takes into account both adverse selection and moral hazard. In this strand, there are different types of politicians (like in adverse selection models), and at the same time there exists imperfect information on politicians' action. The role of elections is two fold: choosing the right type of politician and restraining the politicians' rent seeking activity. 
A question that naturally arises is the following: how do the voters evaluate the performances of the incumbent politician? While there are a host of models in this regard, one recent strand of literature, known as theory of yardstick competition, finds considerable empirical and theoretical attention. The idea is the following: voters judge the performance of the incumbent using the yardstick of performance of the politician in a neighboring state: i.e. the incumbent must perform well relative to the neighbor. Needless to say, such models are well suited to the environment of multiple jurisdictions, e.g. that of a federation.

The models involving both moral hazard and adverse selection have been successfully applied to such yardstick competition. The ideas of relative evaluation and yardstick competition come from the industrial organisation literature (Shleifer,1985). A major paper that exploits the idea within a political economy framework is Besley and Case (1995), who show, using data on US state elections, that vote seeking and tax setting patterns can be predicted by theory of yardstick competition. Besley and Smart (2001) demonstrate that the effect on voter welfare may be ambiguous. While yardstick competition allows the detection of bad incumbents, it also induces more rent extraction by bad incumbents who are never going to be re-elected. Belleflame and Hindricks (2005) show if the re-election effect is strong, then yardstick competition always disciplines the incumbent as well as provides the desired sorting: so yardstick competition can never go "the wrong way". Ellis, Dincer and Waddel (2005) find evidence that decentralization, by allowing yardstick competition among politicians, reduces corruption.

A problem with such a specification is that politician types are not endogenous. For our purpose, we think the first generation moral hazard modelling has the virtue that a single politician, depending on the situation, can be either good or bad. On the other hand, for the yardstick models involving moral hazards, it requires that the voters (as in second movers in a dynamic game of imperfect information) be able to extract signals from incumbent behavior and judge whether the incumbent is good or bad. This might be placing too much importance on voters. Instead, we assume that given a yardstick voting rule to which the voters commit to, the contest is among neighboring incumbents, that is, the actual policymakers.

The present paper broadly belongs to the first generation models, but assumes that the voting rule uses a yardstick criterion. The incumbent can provide a public good and extract rent, which are financed by imposing a distortionary tax on the population. An incumbent derives utility from rent as well as popularity. The popularity index depends on voters' net welfare and esteem/reputation. Reputation is decreasing in rent appropriation. Under yardstick criterion of performance evaluation, the voting behaviour reflects the fact that higher 
relative rent lowers the popularity index of the incumbent. To contrast the performance of yardstick competition, we use a hypothetical case where the absolute performance is used by the voters to evaluate the politician. This is more prevalent in a unitary country, comprising of one head of the state. On the other hand, yardstick competition is more likely to occur in a federal economy, such as India, Australia, Canada, the USA. However, the scope of application of our model is not limited to federal economies. Within the EU, voters may well use the performance of a neighbouring country as a yardstick: the fact that the Spanish economy recently overtook the Italian one (on the basis of GDP per head) has helped the re-election of the Spanish incumbent government. Our model, however, does not applies to autocracies, where changes of governments do not result from democratic processes.

We demonstrate the possibility that yardstick competition itself fails to restrict rent seeking without assigning an ex ante type on the politician. On hindsight, the intuition is the following: the power of judgement is somewhat lost once we use a yardstick criterion. If the politician knows that the voters' judgement is relative, then he has to perform only a "little better" than his neighboring government in order to get re-elected. In equilibrium, there are cases when both of them perform equally bad, and yardstick competition fails to distinguish between them. Thus both the sorting and restraining effect of election may fail.This effect is more acute as we move from perfect to imperfect information environment where the incumbent of a particular province knows his popularity index but not that of the neighboring incumbent. It can be shown that expected rent appropriation under imperfect information is higher than the perfect information case, and is increasing in the noise.

We complement the static setting with a dynamic scenario where each incumbent politician faces an election after a finite, fixed term. The stock of reputation or esteem builds up or decays over time. The incumbent cares for both instantaneous as well as the end-ofterm reputation. The idea that an incumbent politician's long-term interest may restrain his short-term opportunistic behaviour has been well explained by Olson (2000) who made a famous comparison between between a roving bandit and a stationary bandit; see also Dalgic and Long (2006). We show that under unitary performance evaluation, dynamic incentives restrain the politician only if the shadow value of reputation (that measures current and future marginal benefits of increased reputation) is sufficiently high throughout the term. For such a high shadow value to exist, benefits of both instantaneous and end-of-period reputations have to be high enough. On the other hand, in comparison to the static case, dynamic incentives imposes more restriction on rent appropriation under relative performance evaluation. The reason is the following. A high shadow value imposes restriction on current rent 
expropriation. In the case where relative evaluations matter, higher shadow price in one region reduces incentive of rent expropriation in the other region as well.

The present work is divided into the following sections. Section 2 describes the basic model. Sections 3 and 4 compare and contrast unitary evaluation criterion with relative criterion under a static setting. Section 5 analyses the dynamic model. Section 6 concludes.

\section{A Static Model}

Let $\tau_{i}$ be the tax collected from province $i$, and $r_{i}$ be the rent that accrues to the government of province $i$. The amount $\left(\tau_{i}-r_{i}\right) \equiv g_{i}$ is used to supply a local public good. The utility function of the voters in province $i$ is

$$
W\left(g_{i}, \tau_{i}\right)=U\left(g_{i}\right)-C\left(\tau_{i}\right)
$$

where $U($.$) is concave and increasing in g_{i}$, and $C($.$) is convex and increasing in \tau_{i}$. The function $C($.) includes the cost of forgone consumption of private good, as well as distortionary costs associated with non-lump-sum taxation.

The government's objective function, denoted by $G_{i}$, is assumed to be a weighted average of (i) social welfare, (ii) politicians' private benefits from rents, $B\left(r_{i}\right)$, and (iii) the politicians' valuation of the public esteem, denoted by

$$
E_{i}=E_{i 0}-\theta_{i} v_{i}\left(r_{i}\right)
$$

Here $\theta_{i} v_{i}\left(r_{i}\right)$ is a measure of the loss of esteem that arises from the public's perception of rent extraction by politicians, and $E_{i 0}$ is a constant. The function $v_{i}($.$) is strictly convex$ and increasing in $r_{i}, \theta_{i}$ is a positive parameter which reflects the degree of sensitivity of the public. The function $B($.$) is concave and increasing in r_{i}$.

\subsection{Unitary state outcome}

The provincial government chooses $r_{i}$ and $\tau_{i}$ to maximize

$$
G_{i} \equiv U\left(\tau_{i}-r_{i}\right)-C\left(\tau_{i}\right)+B\left(r_{i}\right)+E_{i 0}-\theta_{i} v_{i}\left(r_{i}\right)
$$

It is convenient to decompose this maximization problem into a two-stage problem. In the first stage, for a given $r_{i}$, we determine the optimal $\tau_{i}$, and express this as a function $\tau_{i}\left(r_{i}\right)$. In the second stage, we determine $r_{i}$. 
Thus, the first stage problem consists of solving the optimal provision of public good, for a given $r_{i}$, i.e.

$$
W^{*}\left(r_{i}\right) \equiv \max _{\tau_{i}} U\left(\tau_{i}-r_{i}\right)-C\left(\tau_{i}\right)
$$

In the second stage, the government chooses $r_{i}$ to maximize $G_{i}=W^{*}\left(r_{i}\right)+B\left(r_{i}\right)+E_{i 0}-\theta_{i} v_{i}\left(r_{i}\right)$

The maximization problem (1) yields the first order condition

$$
U^{\prime}\left(\tau_{i}-r_{i}\right)=C^{\prime}\left(\tau_{i}\right)
$$

from which we obtain the optimal amount of tax as a function of $r_{i}$

$$
\tau_{i}=\tau_{i}\left(r_{i}\right)
$$

with

$$
0<\frac{d \tau_{i}}{d r_{i}}=\frac{U^{\prime \prime}}{U^{\prime \prime}-C^{\prime \prime}}<1
$$

Substituting the function $\tau_{i}\left(r_{i}\right)$ into $(1)$, we get

$$
W^{*}\left(r_{i}\right)=U\left(\tau_{i}\left(r_{i}\right)-r_{i}\right)-C\left(\tau_{i}\left(r_{i}\right)\right)
$$

Applying the envelope theorem, we obtain the derivative of the social welfare function with respect to rents

$$
\frac{d W^{*}\left(r_{i}\right)}{d r_{i}}=-U^{\prime}\left(\tau_{i}\left(r_{i}\right)-r_{i}\right)<0
$$

The second derivative is

$$
\frac{d^{2} W^{*}}{d r_{i}^{2}}=-U^{\prime \prime}\left(\tau_{i}\left(r_{i}\right)-r_{i}\right)\left[\frac{d \tau_{i}}{d r_{i}}-1\right]<0
$$

This shows that social welfare is concave in $r_{i}$.

Now, turning to the second step, we find the optimal rent to be sought by the government. From the government's objective function,

$$
G_{i}=W^{*}\left(r_{i}\right)+B\left(r_{i}\right)+E_{i 0}-\theta_{i} v_{i}\left(r_{i}\right)
$$

we get the first order condition

$$
\frac{d G_{i}}{d r_{i}}=W^{* \prime}\left(r_{i}\right)+B^{\prime}\left(r_{i}\right)-\theta_{i} v_{i}^{\prime}\left(r_{i}\right)=0
$$

The second order condition is satisfied because $W^{*}\left(r_{i}\right)$ and $B\left(r_{i}\right)$ are concave in $r_{i}$, and $\theta v\left(r_{i}\right)$ is convex in $r_{i}$.

$$
\frac{d^{2} G_{i}}{d r_{i}^{2}}=W^{*^{\prime \prime}}\left(r_{i}\right)+B_{i}^{\prime \prime}\left(r_{i}\right)-\theta_{i} v_{i}^{\prime \prime}\left(r_{i}\right)<0
$$


Using (6) and (4), we see that the amount of rent optimally chosen by the government can be depicted by the equation

$$
B^{\prime}\left(r_{i}^{o p t}\right)=\theta_{i} v^{\prime}\left(r_{i}^{o p t}\right)-U^{\prime}\left(\tau_{i}\left(r_{i}^{o p t}\right)-r_{i}^{o p t}\right)
$$

The left-hand side of eq (7) is the marginal benefit (MB), and the right-hand side is the marginal cost (MC). Since MB is downward sloping and $\mathrm{MC}$ is upward sloping, the optimal rent is uniquely determined. An increase in $\theta_{i}$ will shift the $\mathrm{MC}$ curve up, and result in a lower amount of rent sought. This result is stated as Proposition 1 below:

Proposition 1: Increased voter sensitivity decreases rent seeking.

Proof: Differentiating the equation (6) to get

$$
\left[W^{*^{\prime \prime}}\left(r_{i}\right)+B_{i}^{\prime \prime}\left(r_{i}\right)-\theta_{i} v_{i}^{\prime \prime}\left(r_{i}\right)\right] d r_{i}-v_{i}^{\prime}\left(r_{i}\right) d \theta_{i}=0
$$

Thus

$$
\frac{d r_{i}}{d \theta_{i}}=\frac{v_{i}^{\prime}\left(r_{i}\right)}{\Delta}<0
$$

where $\Delta \equiv W^{*^{\prime \prime}}\left(r_{i}\right)+B_{i}^{\prime \prime}\left(r_{i}\right)-\theta_{i} v_{i}^{\prime \prime}\left(r_{i}\right)<0$.

\subsection{Relative Evaluation}

Now assume that voters in province $i$ cares about the relative performance (in terms of corruption) of government $i$. Let $\kappa_{i}$ be a parameter, where $\kappa_{i} \in[0,1]$, and define

$$
z_{i} \equiv r_{i}-\kappa_{i} r_{j}
$$

We assume the loss of popularity is proportional to the function $v_{i}\left(z_{i}\right)$ :

$$
v_{i}=v_{i}\left(r_{i}-\kappa_{i} r_{j}\right) \equiv v_{i}\left(z_{i}\right)
$$

with $v_{i}^{\prime}\left(z_{i}\right)>0$ and $v_{i}^{\prime \prime}\left(z_{i}\right)>0$. In the polar case where $\kappa_{i}=0$, we are back to the absolute performance evaluation of the preceding sub-section. We will focus on the other polar case, where $\kappa_{i}=1$; it is convenient to think of this polar case as the limiting case where $\kappa_{i}$ tends to 1 from below.

Given $r_{j}$, the provincial government $i$ chooses $r_{i}$ and $\tau_{i}$ to maximize

$$
G_{i} \equiv U\left(\tau_{i}-r_{i}\right)-C\left(\tau_{i}\right)+B\left(r_{i}\right)+E_{i 0}-\theta_{i} v_{i}\left(r_{i}-\kappa_{i} r_{j}\right)
$$

Again, for any given $r_{i}$, the choice of $\tau_{i}$ must maximize $U\left(\tau_{i}-r_{i}\right)-C\left(\tau_{i}\right)$. So we obtain the function $\tau_{i}=\tau_{i}\left(r_{i}\right)$, exactly as before. Thus

$$
G_{i}=W^{*}\left(r_{i}\right)+B\left(r_{i}\right)+E_{i 0}-\theta_{i} v_{i}\left(r_{i}-\kappa_{i} r_{j}\right)
$$


The first order condition is

$$
\frac{d G_{i}}{d r_{i}}=W^{* \prime}\left(r_{i}\right)+B_{i}^{\prime}\left(r_{i}\right)-\theta_{i} v_{i}^{\prime}\left(r_{i}-\kappa_{i} r_{j}\right)=0
$$

The second order condition is

$$
W^{*^{\prime \prime}}\left(r_{i}\right)+B_{i}^{\prime \prime}\left(r_{i}\right)-\theta_{i} v_{i}^{\prime \prime}\left(r_{i}-\kappa_{i} r_{j}\right)<0
$$

which is satisfied because of the concavity of $W^{*}\left(r_{i}\right)$ and of $B\left(r_{i}\right)$ and the convexity of $v_{i}\left(z_{i}\right)$.

Equation (8) implicitly defines the reaction function

$$
r_{i}=R_{i}\left(r_{j} ; \kappa_{i}, \theta_{i}\right)
$$

where $\kappa_{i}$ and $\theta_{i}$ are regarded as parameters. The slope of the reaction function $R_{i}\left(r_{j} ; \kappa_{i}, \theta_{i}\right)$ can be obtained by applying the implicit function theorem to the following equation

$$
F^{(i)}\left(r_{i}, r_{j} ; \kappa_{i}, \theta_{i}\right) \equiv W^{* \prime}\left(r_{i}\right)+B_{i}^{\prime}\left(r_{i}\right)-\theta_{i} v_{i}^{\prime}\left(r_{i}-\kappa_{i} r_{j}\right)=0
$$

We now show that the reaction function is upward sloping, i.e., $r_{i}$ and $r_{j}$ are strategic complements:

$$
\frac{d r_{i}}{d r_{j}}=\frac{\frac{\partial F^{(i)}}{\partial r_{j}}}{\frac{\partial F^{(i)}}{\partial r_{i}}}=\frac{\kappa_{i} \theta_{i} v_{i}^{\prime \prime}\left(z_{i}\right)}{\theta_{i} v_{i}^{\prime \prime}\left(z_{i}\right)+\Omega\left(r_{i}\right)}>0 \text { if } \kappa_{i}>0
$$

where

$$
\Omega\left(r_{i}\right) \equiv\left[-W^{*^{\prime \prime}}\left(r_{i}\right)-B^{\prime \prime}\left(r_{i}\right)\right]>0
$$

Since

$$
0 \leq \frac{\kappa_{i} \theta_{i} v_{i}^{\prime \prime}\left(z_{i}\right)}{\theta_{i} v_{i}^{\prime \prime}\left(z_{i}\right)} \leq 1
$$

and $\theta_{i} v_{i}^{\prime \prime}\left(z_{i}\right)+\Omega\left(r_{i}\right)>\theta_{i} v_{i}^{\prime \prime}\left(z_{i}\right)$, the slope of the reaction function is positive and strictly less than 1 if and only if $\kappa_{i} \in(0,1]$.

A similar analysis applies to government $j$ 's reaction function $r_{j}=R_{j}\left(r_{i} ; \kappa_{j}, \theta_{j}\right)$. The intersection of the two reaction curves determines a unique Nash equilibrium $\left(r_{i}^{N}, r_{j}^{N}\right)$. It is a stable equilibrium, because the condition $-1<\left(\frac{\partial R_{i}}{\partial r_{j}}\right)\left(\frac{\partial R_{j}}{\partial r_{i}}\right)<1$ is satisfied.

Unlike the unitary case, the voter sensitivity in one region affects the equilibrium rent extraction in both provinces.

Proposition 2: Increased voter sensitivity in one region reduces rent-seeking in both regions if $\kappa_{i}$ and $\kappa_{j}$ are positive.

\section{Proof:}


First, from (9) we can show that an increase in $\theta_{i}$ will shift the reaction curve down (i.e., for any given $r_{j}$, an increase in $\theta_{i}$ will decrease $r_{i}$ ):

$$
\frac{\partial R_{i}}{\partial \theta_{i}}=-\frac{\frac{\partial F^{(i)}}{\partial \theta_{i}}}{\frac{\partial F^{(i)}}{\partial r_{i}}}=\frac{-v_{i}^{\prime}}{\theta_{i} v_{i}^{\prime \prime}\left(z_{i}\right)+\Omega\left(r_{i}\right)}<0
$$

Now, write the Nash equilibrium equations as

$$
\begin{aligned}
& r_{1}^{N}-R_{1}\left(r_{2}^{N}, \kappa_{1}, \theta_{1}\right)=0 \\
& r_{2}^{N}-R_{2}\left(r_{1}^{N}, \kappa_{2}, \theta_{2}\right)=0
\end{aligned}
$$

Then

$$
\left[\begin{array}{cc}
1 & -\frac{\partial R_{1}}{\partial r_{2}^{N}} \\
-\frac{\partial R_{2}}{\partial r_{1}^{N}} & 1
\end{array}\right]\left[\begin{array}{l}
d r_{1}^{N} \\
d r_{2}^{N}
\end{array}\right]=\left[\begin{array}{cc}
\frac{\partial R_{1}}{\partial \theta_{1}} & 0 \\
0 & \frac{\partial R_{2}}{\partial \theta_{2}}
\end{array}\right]\left[\begin{array}{l}
d \theta_{1} \\
d \theta_{2}
\end{array}\right]
$$

The determinant of the matrix is

$$
D=1-\left(\frac{\partial R_{1}}{\partial r_{2}}\right)\left(\frac{\partial R_{2}}{\partial r_{1}}\right)>0
$$

Thus

$$
\begin{gathered}
\frac{d r_{1}^{N}}{d \theta_{1}}=\frac{\frac{\partial R_{1}}{\partial \theta_{1}}}{D}<0 \\
\frac{d r_{2}^{N}}{d \theta_{1}}=\frac{\frac{\partial R_{2}}{\partial r_{1}^{N}} \frac{\partial R_{1}}{\partial \theta_{1}}}{D}<0
\end{gathered}
$$

\subsection{Comparison of rents under relative evaluation and under uni- tary evaluation}

Let us focus in the case where the parameters are the same for both provinces. We have seen above that $\left(r_{1}^{N}, r_{2}^{N}\right)$ depends on $\kappa_{1}$ and $\kappa_{2}$. Under unitary evaluation, $\kappa_{1}=\kappa_{2}=0$. Under symmetric relative evaluation, $\kappa_{1}=\kappa_{2}=\kappa>0$. We consider the effect of a change from $\kappa=0$ to $\kappa=1$. If starting from any $\kappa \in(0,1)$, a small increase in $\kappa$ always increase $\left(r_{i}^{N}, r_{j}^{N}\right)$ then we can conclude that a discrete jump from $\kappa=0$ to $\kappa=1$ results in more rent seeking.

Proposition 3: Relative performance evaluation always generates more rent.

Proof: From (11) and (12),

$$
\left[\begin{array}{cc}
1 & -\frac{\partial R_{1}}{\partial r_{2}^{N}} \\
-\frac{\partial R_{2}}{\partial r_{1}^{N}} & 1
\end{array}\right]\left[\begin{array}{l}
d r_{1}^{N} \\
d r_{2}^{N}
\end{array}\right]=\left[\begin{array}{cc}
\frac{\partial R_{1}}{\partial \kappa_{1}} & 0 \\
0 & \frac{\partial R_{2}}{\partial \kappa_{2}}
\end{array}\right]\left[\begin{array}{l}
d \kappa_{1} \\
d \kappa_{2}
\end{array}\right]
$$


Setting $d \kappa_{1}=d \kappa_{2}=d \kappa$, we find that

$$
\frac{d r_{1}^{N}}{d \kappa}=\frac{\frac{\partial R_{1}}{\partial \kappa}}{D}>0
$$

If we look at voters' welfare $W$, then $\frac{d W_{i}}{d \kappa}=-U_{i}^{\prime}\left(\tau_{i}-r_{i}^{N}\right) \frac{d r_{1}^{N}}{d \kappa}<0$.In other words, increased $\kappa$ reduces voters' welfare.

Remark: The intuition behind proposition 3 is as follows. The incumbent knows that the voters' judgement is relative: he has to perform only a "little better" than his neighboring government in order to get re-elected. In equilibrium, there are cases when both of them perform equally bad, and yardstick competition fails to distinguish between them. Thus both the sorting and restraining effect of election may fail.

\section{Dynamic Rent Appropriation}

So far, we have seen that relative performance evaluation may lose its ability to restrict politicians if the provinces are symmetric in 'punishment'. Now we want to see if the same results apply if the incumbent of region $i$ operates over a time horizon of $[0, T]$. We show that dynamic considerations make the relative evaluation criterion better than the static case in terms of restraining the politician, even if the provinces are otherwise symmetric.

Every $T$ years, there is an election. The chance that the incumbent is re-elected depends on the stock of esteem the electorate has for him at that time. This stock is denoted by $S_{i}(t)$. (We avoid the notation $I_{i}$ because of the possible confusion between flow and stock). Let $\rho_{i}$ be the discount factor of the incumbent politician. He wishes to maximize

$$
\int_{0}^{T} e^{-\rho_{i} t}\left[B\left(r_{i}\right)+\omega_{i} S_{i}(t)\right] d t+e^{-\rho_{i} T} \phi\left(S_{i}(T)\right)
$$

where $\phi\left(S_{i}(T)\right)$ is the politician's perceived expected value of his remaining political life and $\omega_{i}$ refers to the weight that the politician puts on the current stock of reputation.

The stock of esteem/reputation changes over time according to the following dynamic equation

$$
\dot{S}_{i}(t)=U\left(\tau_{i}(t)-r_{i}(t)\right)-C\left(\tau_{i}(t)\right)-\theta_{i} v_{i}\left(r_{i}(t), r_{j}(t)\right)
$$

where $S_{i}(0)$ is given and the incumbent chooses $S_{i}(T)$. 


\subsection{Unitary State}

In this case, $r_{j}$ does not appear in the function $v_{i}$. For simplicity, we assume the linear functional form for $\phi$ :

$$
\phi\left(S_{i}(T)\right)=\sigma_{i} S_{i}(T) \text { where } \sigma>0 .
$$

Let $\mu_{i}$ be the co-state variable associated with the state variable $S_{i}$. The Hamiltonian is

$$
H=B\left(r_{i}\right)+\omega S_{i}+\mu_{i}\left[U\left(\tau_{i}-r_{i}\right)-C\left(\tau_{i}\right)-\theta_{i} v\left(r_{i}\right)\right]
$$

The necessary conditions are

$$
\begin{gathered}
\frac{\partial H}{\partial \tau_{i}}=\mu_{i}\left[U^{\prime}\left(\tau_{i}-r_{i}\right)-C^{\prime}\left(\tau_{i}\right)\right]=0 \\
\frac{\partial H}{\partial r_{i}}=B^{\prime}\left(r_{i}\right)-\mu_{i}\left[U^{\prime}\left(\tau_{i}-r_{i}\right)+\theta_{i} v^{\prime}\left(r_{i}\right)\right]=0 \\
\dot{\mu}_{i}=\rho_{i} \mu_{i}-\omega_{i} \\
\mu_{i}(T)=\sigma_{i}
\end{gathered}
$$

Equation (16) is the transversality condition. It says that the shadow price $\mu_{i}$ at the terminal date $T$ must be equal to the marginal contribution of $S_{i}(T)$ to the salvage value function $\phi\left(S_{i}\right)$. The linear differential equation (15), together with the transversality condition (16) uniquely determine the optimal time path of the co-state variable (shadow price) $\mu_{i}(t)$. Integrating (15), we get

$$
\mu_{i}(t)=\frac{\omega_{i}}{\rho_{i}}+A_{i} e^{\rho_{i} t}
$$

where $A_{i}$ is the constant of integration which can be determined by setting $t=T$ in equation (17):

$$
\mu_{i}(T)=\frac{\omega_{i}}{\rho_{i}}+A_{i} e^{\rho_{i} T}
$$

From this equation and (16) we solve for $A_{i}$

$$
A_{i}=\left(\sigma_{i}-\frac{\omega_{i}}{\rho_{i}}\right) e^{-\rho_{i} T}
$$

The optimal time path of the shadow price is then

$$
\mu_{i}^{*}(t)=\frac{\omega_{i}}{\rho_{i}}+\left(\sigma_{i}-\frac{\omega_{i}}{\rho_{i}}\right) e^{-\rho_{i}\left(T-t_{i}\right)}=\frac{\omega_{i}}{\rho_{i}}\left[1-e^{-\rho_{i}\left(T-t_{i}\right)}\right]+\sigma_{i} e^{-\rho_{i}\left(T-t_{i}\right)}>0
$$

It follows that the shadow price is always positive. Its rate of change is

$$
\frac{d \mu_{i^{*}}}{d t}=\rho_{i}\left(\sigma_{i}-\frac{\omega_{i}}{\rho_{i}}\right) e^{-\rho_{i}\left(T-t_{i}\right)}
$$


which is positive if $\rho_{i} \sigma_{i}>\omega_{i}$ and negative if $\rho_{i} \sigma_{i}<\omega_{i}$.

We now determine the time path of rent $r_{i}(t)$. From equation (13) we can express $\tau_{i}(t)$ as a function of $r_{i}(t)$, independently of the value of $\mu_{i}$ :

$$
\tau(t)=\tau\left(r_{i}(t)\right)
$$

where

$$
0<\tau_{i}^{\prime}\left(r_{i}\right)=\frac{U^{\prime \prime}}{U^{\prime \prime}-C^{\prime \prime}}<1
$$

Equations (19) and (20) are exactly the same as equations (2) and (3) of the static section. Substituting (19) into equation (14) we get

$$
B^{\prime}\left(r_{i}\right)-\mu_{i}^{*}\left[U^{\prime}\left(\tau_{i}\left(r_{i}\right)-r_{i}\right)+\theta_{i} v^{\prime}\left(r_{i}\right)\right]=0
$$

Equation (21) shows that the optimal $r_{i}(t)$ is a function of the optimal shadow price $\mu_{i}^{*}(t)$ which was found in eq (18). Differentiating (21) with respect to time, we get

$$
\left\{B^{\prime \prime}\left(r_{i}\right)-\mu_{i}^{*}\left[\theta v^{\prime \prime}\left(r_{i}\right)+U^{\prime \prime}\left(g_{i}\right)\left(1-\tau_{i}^{\prime}\left(r_{i}\right)\right)\right]\right\} \frac{d r_{i}}{d t}=\left[U^{\prime}\left(\tau_{i}\left(r_{i}\right)-r_{i}\right)+\theta_{i} v^{\prime}\left(r_{i}\right)\right] \frac{d \mu^{*}}{d t}
$$

In view of the inequality (20), the expression inside the curly brackets $\{\ldots\}$ is negative. Hence we deduce from equation $(22)$ that $r_{i}(t)$ is increasing over time if and only if $\mu^{*}(t)$ is decreasing over time, i.e. if and only if $\rho_{i} \sigma_{i}<\omega_{i}$.

Comparing equation (21) with the equation (7) of the static case, we see that dynamic rent is lower than static rent if and only if $\mu^{*}$ is greater than 1 .

Clearly, if $\mu^{*}(T)>1$ (i.e. $\sigma_{i}>1$ ) and $\mu^{*}(t)$ is a decreasing function of $t$, i.e., $\rho_{i}<\omega_{i} / \sigma_{i}$, then,$\mu^{*}(t)>1$ for all $t \leq T$. We thus obtain the following result:

Proposition 4: Under the unitary case, if (i) the politician attaches a high terminal value $\sigma_{i}$ per unit of esteem, (ii) he is patient (i.e. $\rho_{i}$ is small), and (iii) the weight attached to instantaneous esteem is high, then dynamic incentive restricts the politician vis-à-vis the static case.

\subsection{Relative Evaluation}

Under relative evaluation, the equation of motion becomes

$$
\dot{S}_{i}=U\left(\tau_{i}-r_{i}\right)-C\left(\tau_{i}\right)-\theta_{i} v_{i}\left(r_{i}-\kappa_{i} r_{j}\right)
$$

Since the rate of change in the stock of esteem $S_{i}$ depends not only on $r_{i}$ but also on $r_{j}$, the optimal time path of rent extraction by one provincial government depends on what it 
expects the the rent extraction path of the neighboring government will be. Thus the two provincial governments are engaged in a differential game. (See Dockner et al. (2000) for a comprehensive treatment of differential games, with many applications in economics.) The optimality conditions are then, for $i=1,2$,

$$
\begin{gathered}
\frac{\partial H}{\partial \tau_{i}}=\mu_{i}\left[U^{\prime}\left(\tau_{i}-r_{i}\right)-C^{\prime}\left(\tau_{i}\right)\right]=0 \\
\frac{\partial H}{\partial r_{i}}=B^{\prime}\left(r_{i}\right)-\mu_{i}\left[U^{\prime}\left(\tau_{i}-r_{i}\right)+\theta_{i} v_{i}^{\prime}\left(r_{i}-\kappa_{i} r_{j}\right)\right]=0 \text { for } j \neq i \\
\dot{\mu}_{i}=\rho_{i} \mu_{i}-\omega_{i} \\
\mu_{i}(T)=\sigma_{i}
\end{gathered}
$$

Again, we can solve for the optimal time path of the shadow prices:

$$
\mu_{i}(t)=\frac{\omega_{i}}{\rho_{i}}+\left(\sigma_{i}-\frac{\omega_{i}}{\rho_{i}}\right) e^{-\rho_{i}(T-t)} \text { for } i=1,2
$$

Use (23) to express $\tau_{i}$ as function of $r_{i}$ (independent of $\mu_{i}$ ), and substitute into (24) to get

$$
B^{\prime}\left(r_{i}\right)-\mu_{i}\left[U^{\prime}\left(\tau_{i}\left(r_{i}\right)-r_{i}\right)+\theta_{i} v_{i}^{\prime}\left(r_{i}-\kappa_{i} r_{j}\right)\right]=0 \text { for } j \neq i
$$

This equation yields the reaction function

$$
r_{i}=R_{i}\left(r_{j} ; \mu_{i}, \kappa_{i}\right)
$$

with derivative $d r_{i} / d r_{j}$ given by

$$
\left\{B^{\prime \prime}\left(r_{i}\right)-\mu_{i} U^{\prime \prime}\left[\tau_{i}^{\prime}-1\right]-\mu_{i} \theta_{i} v_{i}^{\prime \prime}\right\} d r_{i}+\kappa_{i} \mu_{i} \theta_{i} v_{i}^{\prime \prime} d r_{j}=0
$$

Thus, if $\kappa_{i} \neq 0$

$$
1>\frac{d r_{i}}{d r_{j}}=\frac{\partial R_{i}}{\partial r_{j}}=\frac{\kappa_{i} \mu_{i} \theta_{i} v_{i}^{\prime \prime}}{\mu_{i} \theta_{i} v_{i}^{\prime \prime}+\left[\mu_{i}\left(\tau_{i}^{\prime}-1\right) U^{\prime \prime}-B_{i}^{\prime \prime}\right]}>0 .
$$

Thus the rents are complements, as before.

Note that

$$
\frac{\partial R_{i}}{\partial \mu_{i}}=-\frac{\theta_{i} v_{i}^{\prime}}{\mu_{i} \theta_{i} v_{i}^{\prime \prime}+\left[\mu_{i}\left(\tau_{i}^{\prime}-1\right) U^{\prime \prime}-B_{i}^{\prime \prime}\right]}<0
$$

The intersection of the two reaction functions $r_{i}=R_{i}\left(r_{j} ; \mu_{i}, \kappa_{i}\right)$ and $r_{i}=R_{j}\left(r_{i}, \mu_{j}, \kappa_{j}\right)$ determines the rents obtained at time $t$ when we substitute the value for $\mu_{i}(t)$ and $\mu_{j}(t)$ from equation (25).

Now let us show how an increase in $\sigma_{j}$ (hence an increase in $\left.\mu_{j}(t)\right)$ affects the equilibrium rents at time $t$ in all provinces. Using equation (27), we write the system of equations

$$
r_{1}^{N}(t)-R_{1}\left(r_{2}^{N}(t), \mu_{1}(t), \kappa_{1}\right)=0
$$




$$
r_{2}^{N}(t)-R_{2}\left(r_{1}^{N}(t), \mu_{2}(t), \kappa_{2}\right)=0
$$

Holding $\mu_{1}(t)$ constant, differentiate the system with respect to $\mu_{2}(t)$ :

$$
\left[\begin{array}{cc}
1 & -\frac{\partial R_{1}}{\partial r_{2}^{N}} \\
-\frac{\partial R_{2}}{\partial r_{1}^{N}} & 1
\end{array}\right]\left[\begin{array}{l}
\frac{d r_{1}^{N}}{d \mu_{2}} \\
\frac{d r_{2}^{N}}{d \mu_{2}}
\end{array}\right]=\left[\begin{array}{c}
0 \\
\frac{\partial R_{2}}{\partial \mu_{2}}
\end{array}\right]
$$

Hence

$$
\frac{d r_{1}^{N}}{d \mu_{2}}=\frac{1}{\Delta} \frac{\partial R_{2}}{\partial \mu_{2}}<0
$$

where

$$
\Delta \equiv 1-\frac{\partial R_{2}}{\partial r_{1}^{N}} \frac{\partial R_{1}}{\partial r_{2}^{N}}>0
$$

Thus we have proved the following proposition.

Proposition 5: The higher is the neighboring incumbent's shadow value of esteem $\left(\mu_{j}(t)\right)$, the lower is $r_{i}(t)$ in province $i$.

\section{Conclusion}

In this paper, we analyzed the extent to which elections can make a politician benevolent. We assume that politicians provide a local public good to their constituency and appropriate some rent. The public good and the rent are financed by taxing the local populace. The tax imposes distortion cost on the local populace. If the politicians appropriate rent, they are likely to lose their reputation. What is crucial here is how the electorate views politicians' performance. Depending on the electorates' institutional structure, there are two possibilities. It may be the case that politicians' absolute performance matters: this is the case for unitary electorate, e.g. a nation, or when information about the neighboring electorate is costly. On the other hand, the voters may compare the incumbent's performance with that of the neighboring electorate's incumbent. This is more prominent within a federal country or a confederation of countries (such as E.U.), where such information is readily available. We discussed the conditions under which a unitary criterion does strictly better than a relative criterion. We found that when performance evaluation depends on the difference between rents, the unitary criterion (that closely mimics the corresponding relative criterion) does strictly better than the relative criterion. However, introduction of dynamic considerations imposes more restrictions on the politicians, through the shadow price effect, under the relative evaluation than unitary performance evaluation.

We would like to mention some areas to which the current research may be extended. The first issue is theoretical in nature. In the present paper, the public good is a flow, 
but often there exist public goods which exhibit dynamic build-up over time. If politicians' reputation depends on both public good and rent, a 'stock' public good may allow for more rent diversion.

Second, the following testable hypotheses emerge, which can be evaluated using real world data:

(a) In a democracy where elections are very frequent (such that, at the limit, the decision making process degenerates into a static setting), incumbents may be less honest than in a country where the incumbents are appointed for a longer term.

(b) Within countries where the incumbents are appointed for a longer term (i.e. dynamic considerations matter), politicians in a federal country (where the voters employ relative performance evaluation) are likely to be more honest than their unitary-nation counterparts.

Thus there exists a challenging agenda for future research.

Acknowledgements: We thank an anonymous referee for helpful comments. This research is supported by grants from Canada's Social Sciences and Humanities Research Council (SSHRC), and from Quebec's granting agency FQRSC.

\section{References}

[1] Barro, R. (1973), "The control of politicians: an economic model", Public Choice, Vol. 14 No.1, pp. 19-42.

[2] Belleflamme, P. and Hindriks, J. (2005), "Yardstick competition and political agency problems", Social Choice and Welfare, Vol. 24 No. 1, pp 155-169.

[3] Besley, T., and Case, A. (1995), "Incumbent behavior: vote-seeking, tax-setting, and yardstick competition", American Economic Review, Vol.85 No. 1, pp. 25-45.

[4] Besley, T., and Smart, M. (2001), "Globalization and electoral accountability", typescript.

[5] Dalgic, E. and Long, N.V. (2006), "Corrupt Local Government as Resource Farmers: the Helping Hand and the Grabbing Hand," European Journal of Political Economy, Vol. 22 No.1, pp. 115-138.

[6] Dockner, E. J., Jorgensen, S., Long, N.V., and Sorger, G. (2000), Differential Games in Economics and Management Science, Cambridge University Press, Cambridge. 
[7] Ellis, C., Dincer, O., and Waddel, G. (2005), "Corruption, decentralization and yardstick competition", University of Oregon Working Paper 2005-05.

[8] Ferejohn, J. (1986), "Incumbent performance and electoral control", Public Choice, Vol. 50 No.1, pp. 5-26.

[9] Olson, M., (2000) Power and Prosperity: Outgrowing Communist and Capitalist Dictatorships, Basic Book, New York.

[10] Rogoff, K., and Sibert, A. (1988), "Elections and macroeconomic policy cycle", Review of Economic Studies, Vol.55 No.1, pp. 1-16.

[11] Rogoff, K. (1990), "Equilibrium political budget cycles", American Economic Review, Vol. 80 No. 1, pp. 21-36.

[12] Shleifer, A. (1985), "A theory of yardstick competition", RAND Journal of Economics, Vol. 16 No. 3, pp. 319-327

[13] United Nations Human Development Report (2002), Deepening Democracy in a Fragmented World, United Nations, New York. 


\section{CESifo Working Paper Series}

for full list see www.cesifo-group.org/wp

(address: Poschingerstr. 5, 81679 Munich, Germany, office@cesifo.de)

2281 Katrin Assenmacher-Wesche and M. Hashem Pesaran, A VECX* Model of the Swiss Economy, April 2008

2282 Christophe Rault, Robert Sova and Ana Maria Sova, Modeling International Trade Flows between CEEC and OECD Countries, April 2008

2283 Timo Boppart, Josef Falkinger, Volker Grossmann, Ulrich Woitek and Gabriela Wüthrich, Qualifying Religion: The Role of Plural Identities for Educational Production, April 2008

2284 Armin Falk, David Huffman and W. Bentley MacLeod, Institutions and Contract Enforcement, April 2008

2285 Axel Dreher and Stefan Voigt, Does Membership in International Organizations Increase Governments' Credibility? Testing the Effects of Delegating Powers, April 2008

2286 Xavier Freixas and Bruno M. Parigi, Lender of Last Resort and Bank Closure Policy, April 2008

2287 Regina Dionisius, Samuel Muehlemann, Harald Pfeifer, Günter Walden, Felix Wenzelmann and Stefan C. Wolter, Cost and Benefit of Apprenticeship Training - A Comparison of Germany and Switzerland, April 2008

2288 Francesco Daveri and Cecilia Jona-Lasinio, Off-Shoring and Productivity Growth in the Italian Manufacturing Industries, April 2008

2289 Mikael Priks, Do Surveillance Cameras Affect Unruly Behavior? A Close Look at Grandstands, April 2008

2290 Marianna Belloc and Daniela Federici, A Two-Country NATREX Model for the Euro/Dollar, April 2008

2291 Nicolas Treich, The Value of a Statistical Life under Ambiguity Aversion, April 2008

2292 J. Atsu Amegashie, Socially-Tolerable Discrimination, April 2008

2293 M. Hashem Pesaran and Andreas Pick, Forecasting Random Walks Under Drift Instability, April 2008

2294 Steven Brakman, Gus Garita, Harry Garretsen and Charles van Marrewijk, Unlocking the Value of Cross-Border Mergers and Acquisitions, May 2008

2295 Eric O’N. Fisher and Kathryn G. Marshall, The Structure of the American Economy, May 2008 
2296 Claudia M. Buch and Martin Schlotter, Regional Origins of Employment Volatility: Evidence from German States, May 2008

2297 Helmuth Cremer, Philippe De Donder, Dario Maldonado and Pierre Pestieau, Taxing Sin Goods and Subsidizing Health Care, May 2008

2298 Reinhilde Veugelers and Frederick van der Ploeg, Reforming European Universities: Scope for an Evidence-Based Process, May 2008

2299 Jon H. Fiva and Lars J. Kirkebøen, Does the Housing Market React to New Information on School Quality?, May 2008

2300 Tina Klautke and Alfons J. Weichenrieder, Interest Income Tax Evasion, the EU Savings Directive, and Capital Market Effects, May 2008

2301 Harald Badinger and Peter Egger, GM Estimation of Higher Order Spatial Autoregressive Processes in Panel Data Error Component Models, May 2008

2302 Jan K. Brueckner, Slot-Based Approaches to Airport Congestion Management, May 2008

2303 Sören Blomquist, Vidar Christiansen and Luca Micheletto, Public Provision of Private Goods and Nondistortionary Marginal Tax Rates, May 2008

2304 Dan Anderberg and Alessandro Balestrino, The Political Economy of Post-Compulsory Education Policy with Endogenous Credit Constraints, May 2008

2305 Tomer Blumkin, Yoram Margalioth and Efraim Sadka, The Role of Stigma in the Design of Welfare Programs, May 2008

2306 Vesa Kanniainen and Paolo M. Panteghini, Tax Neutrality: Illusion or Reality? The Case of Entrepreneurship, May 2008

2307 Thomas Dohmen, Armin Falk, David Huffman and Uwe Sunde, The Intergenerational Transmission of Risk and Trust Attitudes, May 2008

2308 Guglielmo Maria Caporale and Mario Cerrato, Using Chebyshev Polynomials to Approximate Partial Differential Equations, May 2008

2309 Peter Egger and Doina Maria Radulescu, Labour Taxation and Foreign Direct Investment, May 2008

2310 Laurent Linnemer, Dissipative Advertising Signals Quality even without Repeat Purchases, May 2008

2311 Jordi Jofre-Monseny and Albert Solé-Ollé, Which Communities should be afraid of Mobility? The Effects of Agglomeration Economies on the Sensitivity of Firm Location to Local Taxes, May 2008 
2312 Andreas Haufler and Ferdinand Mittermaier, Unionisation Triggers Tax Incentives to Attract Foreign Direct Investment, May 2008

2313 Ronel Elul and Piero Gottardi, Bankruptcy: Is it enough to Forgive or must we also Forget?, May 2008

2314 Andreas Irmen and Johanna Kuehnel, Productive Government Expenditure and Economic Growth, May 2008

2315 Beate Henschel, Carsten Pohl and Marcel Thum, Demographic Change and Regional Labour Markets: The Case of Eastern Germany, May 2008

2316 Gabriel Felbermayr, Wido Geis and Wilhelm Kohler, Restrictive Immigration Policy in Germany: Pains and Gains Foregone?, May 2008

2317 Michael Hofmann, Gerhard Kempkes and Helmut Seitz, Demographic Change and Public Sector Budgets in a Federal System, May 2008

2318 Paul De Grauwe, Macroeconomic Modeling when Agents are Imperfectly Informed, June 2008

2319 Johann K. Brunner and Susanne Pech, Optimum Taxation of Inheritances, June 2008

2320 Thomas Eichner and Marco Runkel, Corporate Income Taxation of Multinationals in a General Equilibrium Model, June 2008

2321 Rainald Borck and Matthias Wrede, Subsidies for Intracity and Intercity Commuting, June 2008

2322 Patricia Apps and Ray Rees, Testing the Pareto Efficiency of Household Resource Allocations, June 2008

2323 Amihai Glazer, Vesa Kanniainen and Panu Poutvaara, Firms' Ethics, Consumer Boycotts, and Signalling, June 2008

2324 Claudia M. Buch, Jörg Döpke and Kerstin Stahn, Great Moderation at the Firm Level? Unconditional vs. Conditional Output Volatility, June 2008

2325 Helmuth Cremer, Philippe De Donder, Dario Maldonado and Pierre Pestieau, Forced Saving, Redistribution and Nonlinear Social Security Schemes, June 2008

2326 M. Hashem Pesaran and Paolo Zaffaroni, Optimal Asset Allocation with Factor Models for Large Portfolios, June 2008

2327 Harald Badinger and Peter Egger, Horizontal versus Vertical Interdependence in Multinational Activity, June 2008

2328 Jan K. Brueckner and Harris Selod, A Theory of Urban Squatting and Land-Tenure Formalization in Developing Countries, June 2008 
2329 Paolo M. Panteghini, Corporate Debt, Hybrid Securities and the Effective Tax Rate, June 2008

2330 Guglielmo Maria Caporale, Juncal Cuñado and Luis A. Gil-Alana, Modelling Long-Run Trends and Cycles in Financial Time Series Data, June 2008

2331 Avi Ben-Bassat and Momi Dahan, Social Identity and Voter Turnout, June 2008

2332 Martin R. West and Ludger Wößmann, "Every Catholic Child in a Catholic School”: Historical Resistance to State Schooling, Contemporary Private Competition, and Student Achievement across Countries, June 2008

2333 Erkki Koskela and Panu Poutvaara, Outsourcing and Labor Taxation in Dual Labor Markets, June 2008

2334 Philippe Choné and Laurent Linnemer, Optimal Litigation Strategies with Signaling and Screening, June 2008

2335 Albert Solé-Ollé and Pilar Sorribas-Navarro, Does Partisan Alignment Affect the Electoral Reward of Intergovernmental Transfers?, June 2008

2336 Antonio Cabrales and Piero Gottardi, Markets for Information: Of Inefficient Firewalls and Efficient Monopolies, June 2008

2337 Sumon Majumdar and Sharun W. Mukand, The Leader as Catalyst - on Leadership and the Mechanics of Institutional Change, June 2008

2338 Ulrich Hange, Tax Competition, Elastic Labor Supply, and Growth, June 2008

2339 Guy Laroque and Bernard Salanié, Does Fertility Respond to Financial Incentives?, June 2008

2340 Adriano Paggiaro, Enrico Rettore and Ugo Trivellato, The Effect of Extending the Duration of Eligibility in an Italian Labour Market Programme for Dismissed Workers, June 2008

2341 Helmut Seitz, Minimum Standards, Fixed Costs and Taxing Autonomy of Subnational Governments, June 2008

2342 Robert S. Chirinko, Leo de Haan and Elmer Sterken, Asset Price Shocks, Real Expenditures, and Financial Structure: A Multi-Country Analysis, July 2008

2343 Wolfgang Leininger, Evolutionarily Stable Preferences in Contests, July 2008

2344 Hartmut Egger and Udo Kreickemeier, Fairness, Trade, and Inequality, July 2008

2345 Ngo Van Long and Bodhisattva Sengupta, Yardstick Competition, Corruption, and Electoral Incentives, July 2008 